\title{
On the reliability of reusing bottom ash from municipal solid waste incineration as aggregate in concrete
}

\author{
Alessandro Abbà ${ }^{\mathrm{a}}$, Maria Cristina Collivignarelli ${ }^{\mathrm{a}}$, Sabrina Sorlini $^{\mathrm{b}}$, Matteo Bruggi ${ }^{\mathrm{c}}$ \\ a Department of Civil Engineering and Architecture, University of Pavia, Via Ferrata 1, 27100 Pavia, Italy; \\ abba78@unipv.it; mcristina.collivignarelli@unipv.it; tel. +39 0382 985314, fax +390382985589. \\ b Department of Department of Civil Engineering, Architecture, Land, Environment and Mathematics, University \\ of Brescia, via Branze 43, 25123 Brescia, Italy; sabrina.sorlini@ing.unibs.it \\ c Department of Civil and Environmental Engineering, Politecnico di Milano, Milano, Piazza Leonardo da Vinci, \\ 32, 20133 Milano, Italy; matteo.bruggi@ polimi.it
}

\begin{abstract}
The present work concerns an experimental investigation on the use of residues derived from fluidized bed incinerators as aggregates for concrete. Concrete mixtures were obtained from conventional mix designs used in the production of unreinforced precast elements by partial replacement of natural aggregates with recycled components. The characterization was performed by means of physical and mechanical tests according to the prescriptions of the Italian technical code for construction, with special attention to the probabilistic evaluation of the compressive strength and an investigation of the tensile behavior of the considered specimens. The simplified statistical analysis shows that mixtures containing recycled aggregates may achieve characteristic values of the compressive strength that are very close to the performance of conventional mix designs that are commonly used in the investigated applications. The average compressive strength and the material reliability, i.e. the scattering of results, of concretes containing recycled aggregates are both comparable with those of the reference concrete. Conversely, an investigation on the tensile strength points out a lower performance for
\end{abstract}


mix designs including recycled aggregates. In both cases, the adoption of $42.5 \mathrm{R}$ cement is found to remarkably improve experimental results, i.e. to reduce the gap between the performance of concretes containing recycled aggregates and the reference concrete.

\section{Keywords}

Concrete, compressive strength, recycling, statistical methods.

\section{Introduction}

The production of concrete in Italy, in 2010, despite the economic crisis, amounted to 98.2 million of $\mathrm{m}^{3}$ [1]. According to the Annual Review of the European Aggregate Association, in Italy, in 2010 the total production of aggregates was equal to 300 million tons; $45 \%$ of this value (135 million tons) was used for ready mix concrete, precast concrete and architectural concrete products [2].

Since natural aggregates have been depleting over time, in the last ten years the attention towards the use of alternative materials has grown; this choice is particularly attractive also within the modern context of the green buildings, where recycled materials are required. Recent legislation is addressed to promote the use of recycled aggregate in concrete both at European [3] and national level [4]. Different recycled materials (derived from processing, sorting and recovery of wastes) can be employed for this purpose [5, 6]. Among these materials, the bottom ash derived from Municipal Solid Waste Incineration (MSWI) represent a promising perspective due to their increasing availability and their chemical and physical properties. Waste incineration is growing at very high rates, moving from 6\% in 1996 to $16 \%$ in 2010 with respect to the global waste production. Since the global production of municipal solid waste in Italy, 
in 2010, was 5.2 million tons [7], a production of bottom ash approximately equal to $840,000 \mathrm{t}$ was estimated.

The reuse of MSWI bottom ash for the manufacturing of concrete mixtures has been studied by different authors [8-13]. The main problems concern concrete expansion and cracking, due to the development of gaseous hydrogen produced by the corrosion of some metals, mainly aluminum, in an alkaline environment. The expansion could be reduced by the following pre-treatments on the residues: iron removal, sieving and washing [14], aging for about two months [15], vitrification and subsequent crushing [10]. Moreover, the environmental suitability of concrete containing residues from MSWI is an important issue already investigated by some authors [14, 16-18].

However, the high heterogeneity of these residues can determine a significant variability of concrete mechanical properties [13]. The bottom ashes generated by a fluidized bed reactor are generally suitable for reuse as recycled aggregate for concrete, because they are more homogenous than the bottom ashes derived from a mass burning kiln. This is due to a more complete MSW combustion and the selection of waste prior to incineration [19].

Concrete quality is controlled during its production with the aim of ensuring the design requirements prescribed by technical codes; this becomes an issue that is even more important if wastes are used in the mixture.

Probability-based criteria are usually adopted to ensure that concrete attains its required properties, see e.g. [20]. In the scientific literature many authors have used a statistical evaluation in order to control the quality of concrete and to predict its strength [21]. This approach is useful especially in the case of waste recovery in concrete [22-24]. 
This work presents an experimental investigation on the reuse of bottom ash and exhausted sand derived from fluidized bed incinerators as additional aggregates in concrete. Concrete mixtures are obtained from a conventional mix design by partial substitution of natural aggregates with recycled components. Concepts from the probabilistic theory and material technology are applied to meet the prescriptions of standard building codes for the evaluation of the characteristic compressive strength of concrete. This allows to investigate the reliability of some concrete mixtures containing recycled aggregates with respect to the conventional mix designs.

\section{Material and methods}

\subsection{Bottom ash and exhausted sand}

The residues, classified in the European Waste Code as non-dangerous wastes, were firstly characterized with respect to their granulometric properties, while their chemical composition was subsequently analyzed.

Exhausted sand (Fig. 1(a)) shows a $0 \mathrm{~mm}-2 \mathrm{~mm}$ granular distribution; bottom ash (Fig. 1(b)) has a granulometric size between $0 \mathrm{~mm}$ and $20 \mathrm{~mm}$. These residues are generated from MSW incineration: therefore, there is a significant presence of ferrous and non-ferrous metals which do not change during the heat treatment. Before reuse as recycled aggregate in concrete bottom ash was sifted with a maximum grain size of 10 mm while no treatment was applied to the exhausted sand.

Table 1 reports the chemical composition of both the two residues considered in this study, as compared to the typical values measured on natural aggregates. Concerning the oxides, the content of $\mathrm{SiO}_{2}$ in exhausted sand is higher than bottom ash while higher amounts of the other oxides, especially $\mathrm{CaO}$ and $\mathrm{Al}_{2} \mathrm{O}_{3}$, are found in bottom ash. The 
content of metals in bottom ash is dependent both on the chemical composition of the MSW fed to the incinerator and on their volatility [25]. The elements that show significant concentration in the bottom ash are total copper and lead (both higher than natural soil) and zinc, while only traces of chromium VI are observed.

Exhausted sand presents a similar composition, exhibiting high concentrations of total copper (also in this case, higher than natural soil), lead and zinc. Generally, they have also a higher content of zinc, total chromium, nickel and tin with respect to the bottom ash; this fact was probably due to several recirculation of the sand inside the burning chamber during waste combustion, that increased the concentration of pollutants contained in the sand itself.

\subsection{Mix design of concrete mixtures with natural and recycled aggregates}

Different concrete mixtures (Table 2) were casted using both natural and recycled aggregates with the aim to produce low strength concrete suitable for precasted elements such as flat interlocking tiles or manholes for the construction industry. The adoption of a low strength class is suggested by the need to investigate basic applications in which steel reinforcement is not required.

The mixture called "Ref" was chosen as the reference concrete composed only of natural aggregates. Two additional mix designs were considered to address the effect of partial substitution of natural aggregates with recycled residues: label “Ash400” refers to a mixture containing bottom ash, while label "San200" marks the reuse of exhausted sand. Each one of the above mixtures was investigated taking into account two different cement classes, i.e. a CEM II B LL 32.5 R (hereinafter called CEM32.5R) and a CEM II A LL 32.5 R (hereinafter called CEM42.5R), produced by “Buzzi Unicem”. The latter 
allows to remove the casted elements from their formworks in a shorter time than

CEM32.5R, which is generally employed when precasting machines work at low job rate. For this reason, both cements have been considered in the experimental campaign.

Fig. 2 represents the granular distribution of natural and recycled aggregates while Fig. 3 reports the granulometric curves of concrete solid fractions. Exhausted sand exhibits a granulometric curve that is very similar to natural sand while bottom ash has a widerange distribution that seems ideally tailored for the partial substitution of both the small-size natural component (sand) and the middle-size one (fine gravel). The above features were mainly taken into account to design the mixtures presented in Table 2. The different aggregates were combined in order to obtain a granulometric curve for the solid fractions in full agreement with the reference one, as found in Fig. 3. This allows to focus on the effect of a partial substitution of natural aggregates in standard mix designs, for a fixed porosity of the solid fraction.

Technical literature on concrete also reports the so-called "optimal granulometric curves", i.e. size distribution diagrams referred to the solid fraction of the mixture that allow for achieving the maximum density for a prescribed workability of concrete. According to Bolomey, the optimal granulometric curve that follows the minimum void percentage is provided by:

$$
G=100 \frac{A-C+(100-A) \sqrt{d / D}}{100-C}
$$

In the above formula, $\mathrm{d}$ is the current aggregate diameter, $\mathrm{D}$ is the maximum diameter, $\mathrm{A}$ is a parameter that depends on the required workability and $\mathrm{C}$ the cement percentage with respect to the solid fraction of concrete. Taking into account that the considered standard mixtures have a remarkable water/cement ratio, the workability prescription to be included in the Bolomey curve may follow the literature suggestion for this 
condition, that means $\mathrm{A}=8$. The Bolomey curve may be considered as an analytical reference to compare the effect of the granulometric variety of a mixture with respect to the achieved concrete strength. A diagram that accurately approximates the Bolomey function provides a lower void percentage, i.e. a lower porosity, thus increasing the composite strength. Fig. 3 also shows a comparison of the granulometric diagrams of the mixtures herein investigated with respect to a Bolomey curve with a maximum diameter $\mathrm{D}=10 \mathrm{~mm}$. It can be noticed that the three mixtures are very similar each other, even if the mix design called "Ash400" may provide a very small increase in the density for large diameters.

The rheology of the concrete mixtures casted with recycled aggregates has been investigated through slump tests. All mixtures were classified as slump class S4: this high slump class (fluid class) is suitable for an effective cast within any mould of complex geometry. No remarkable slump loss was encountered when casting concretes containing recycled aggregates with respect to the reference mix design, meaning that the adoption of recycled aggregates was found to affect negligibly the workability of the mixtures. Due to the low requirements in terms of compressive strength, the mix design for the considered standard mixtures can rely on a remarkable water/cement ratio and do not call for the adoption of any superplasticizer. Although superplasticizers allow increasing the slump of concrete while preserving its strength, they were not used as their performance is well-known to be strongly affected by the use of recycled aggregates $[26,27]$. 
All the mixtures were stirred using a horizontal axis blending machine, with a volume of $0.5 \mathrm{~m}^{3}$. For each one of the concrete mixture presented in Table 2, forty cubic specimens (side $15 \mathrm{~cm}$ ) and six cylinders (diameter $15 \mathrm{~cm}$ and height $30 \mathrm{~cm}$ ) were casted and suitably compacted. According to the standard UNI EN 12390-2 [28], all the formworks were removed three days after and the subsequent curing phase took place in water at a temperature of $(20 \pm 2)^{\circ} \mathrm{C}$.

The $28^{\text {th }}$ day after casting, all the specimens were subjected to experimental tests in order to measure the mechanical strength of the considered mixtures. Cubic specimens were used for compressive strength (according to the instructions reported in UNI EN 12390-3 [29]), while cylindrical specimens were used for splitting tests for the determination of the tensile strength (UNI EN 12390-6 [30]).

Rigid plastic moulds have been employed in the experimental campaign to provide a good reproducibility in terms of strength. 


\section{Results and discussion}

\subsection{Compressive strength}

The Italian regulatory framework for the construction industry mainly consists in the Building Code DM 14/01/2008 [4], which prescribes a statistical control of the material strength (acceptance control). This control has the aim of providing suitable safety margins to the design process and the subsequent construction, notwithstanding the small number of specimens that are generally available to perform controls in construction sites. As recalled in the sequel, the italian code prescribes a type " $A$ " test, which is performed for concrete pours involving less than $300 \mathrm{~m}^{3}$ of homogeneous mixture and simply needs a check on the minimum and average values of the strength of 6 cubic specimens. For pours involving more than $1500 \mathrm{~m}^{3}$ of homogeneous concrete, a simplified "statistical control of acceptance" (type "B" test) is necessary and requires 30 cubic specimen (at least) to additionally compute the standard deviation of the results. The above procedures allow for a homogeneous comparison of the considered concrete mixtures according to a conventional framework that descends from safety requirements derived from simplified statistical concepts. The population of specimens investigated in the presented experimental campaign is comparable with those required in the aforementioned acceptance controls. The statistical analysis reported in the sequel must be therefore intended as a first investigation performed in the mainstream of the simplified prescriptions for acceptance controls prescribed by the codes. Indeed, a full assessment of the statistical properties of the considered mixtures would require a much wider population of specimens.

The procedures of control described above cope with non-deterministic quantities that can be described via probabilistic concepts [31]. To this purpose, random variables are 
commonly adopted to represent loads, structure responses and material properties, which play a fundamental role in the definition of the overall structural strength. The uncertainty peculiar to materials depends on several issues that are mainly due to the variability of the production process. Referring to concrete, the scattering of the results is intimately tied to the features of each one of the components and to the methods adopted to cast the mixtures. Having the aim of investigating concrete with recycled aggregates, it is therefore useful to set up a preliminary comparison between the probabilistic properties of the reference mixtures and the concrete obtained with partial substitution of natural aggregates.

A first analysis concerns the average strength $\left(\mathrm{R}_{\mathrm{cm}}\right)$, and the coefficient of variation (C.o.v.) of each mixture detailed in Table 2 . $\mathrm{R}_{\mathrm{cm}}$ represents the reference value for the considered population, while C.o.v. provides an immediate non-dimensional index of the scattering of results with respect to the average value.

Fig. 4 and 5 show the mean values and the coefficients of variation for the compressive strength, as found for each one of the mixtures detailed in Table 2. The results are grouped into two classes, depending on the adopted cement. Black bars regard reference mixtures used in the precasting plant. The average compressive strengths are around 15 $\mathrm{MPa}$ (cement CEM32.5R) and $20 \mathrm{MPa}$ (cement CEM42.5R). The use of "in situ" casting devices, the accurate control during the blending process, the adoption of aggregates with prescribed mechanical properties and the homogeneous concrete curing conditions allow to achieve coefficients of variation that are extremely small (about $4 \%$ ), providing a limited scattering of results. Concrete mixtures containing the incineration residues were compared to the reference mixtures to assess the effect of partial substitution of natural aggregates. 
Mixture "Ash400" adopts bottom ash in partial replacement of natural fine gravel and sand, according to an assigned amount $400 \mathrm{~kg} / \mathrm{m}^{3}$. The adoption of such a percentage of recycled aggregates does not affect the average concrete strength. Concerning the coefficient of variation, a very small scattering is found for cement CEM42.5R, while a more extended range is shown in the case of CEM32.5R. In both cases, the value is lower than the admissibility threshold fixed at $15 \%$. Beyond this value, additional investigations are prescribed by the Building Code in order to assess the suitability of the adopted materials.

Mixture "San200" addresses the partial replacement of the small-sized fraction of the natural aggregates with exhausted sand. The discussion reported above with respect to bottom ash may be straightforwardly extended to the recycled sand. In this case, the coefficient of variation is much less sensitive with respect to the type of the cement. The analysis of the above statistical parameters allows for a discussion on the adoption of incineration residues as aggregate in concrete mixtures. Fig. 4 and 5 suggest in fact that a suitable amount of residues may be used in substitution of natural aggregates, without reducing concrete performance.

This issue can be further investigated by means of more advanced methods that are proper to the probabilistic literature applied to materials science, see e.g. [32]. Mechanical properties may be handled in terms of random variables that may be usefully described via probability density functions.

Random variables that are commonly used to evaluate the statistics of strength of construction materials are the Gaussian distribution, the Lognormal distribution and the Weibull distribution. Each one of them only depends on two parameters [33]. The Gaussian scheme is the reference model adopted by international building codes to 
address the variability of the compressive strength of concrete and to operate simplified acceptance controls [34]. The distribution is called Lognormal if the logarithm of the random variable is a Gaussian distribution and may assume only positive signs, as in the case of strengths . The Weibull model is suggested if a propagation of an intrinsic defect may lead to a brittle collapse of the material that is still far from a plastic phase. The available literature has demonstrated that the Weibull distribution is well-suited to fit results for compressive tests of high strength concretes or innovative mixtures, such as fiber-reinforced ones [35].

According to the classical assumption of the Gaussian distribution, Fig. 6 (a) and 6(b) show the probability density functions for the mixture considered in Table 2 , taking into account that they may be easily derived from the mean values and the coefficients of variations presented in Fig. 4 and 5. Each one of the curves evidences the average values (abscissa of the symmetry axis) and the scattering intervals ("opening" of the "bell distribution") of the strength. For both the cements, the mixtures with recycled slag present distributions that are very similar to the reference (black) curves for concretes with natural aggregates. The only exception is the more pronounced scattering for the mix design "Ash400" with cement CEM32.5R.

Fig. 7(a) and 7(b) show the result of a fitting procedure aimed at finding the best probability function for the statistical description of the compressive strength of each one of the considered mixtures. To this purpose, the analytic test of KolmogorovSmirnov [32] was repeatedly applied to the available sets of experimental data with the aim of defining the best-fitting distribution among the three previously outlined, i.e. Gaussian, Lognormal and Weibull. The Kolmogorov-Smirnov statistic (K-S test) allows to quantify the distance between an empirical distribution function of the 
considered sample and the cumulative distribution function of the reference distribution, herein Gaussian, Lognormal and Weibull. The test is very sensitive to differences in both location and shape of the empirical distribution function and may be therefore used for an affordable choice of the reference distribution function that provides the best fit with the available data.

Tables 3 and 4 detail the achieved results, referring to Gaussian distributions and to the outcome of the best-fitting procedure (K-S test) respectively. A direct comparison of the Gaussian distributions in Fig. 6 and the non-Gaussian ones in Fig. 7 allows to conclude that the two sets of probabilistic approximations do not exhibit relevant differences. It must be pointed out that the characteristic strength of the material mainly depends on the lower tails of the probability distribution functions. This means that further investigations are needed to assess the strength characteristics of the considered mixtures, notwithstanding the similarities outline above.

The statistical analysis of experimental tests is a valuable instrument to perform the acceptance controls on concrete quality as prescribed by the Building Codes. The number of available tests (40 cubic specimens for each mixture) suggests to implement a control strategy that is very close to the above mentioned type " $\mathrm{B}$ " test, that is a simplified statistical procedure. To fulfill the acceptance control, the following relations must hold:

$$
\begin{aligned}
& R_{c 1} \geq R_{c k}-3.5 \mathrm{MPa} \\
& R_{c m} \geq R_{c k}+1.4 \mathrm{~s}
\end{aligned}
$$

where $R_{c 1}$ stands for the lowest outcome among all the strength tests, $R_{c m}$ is their average value, $s$ is the standard deviation and $R_{c k}$ is the characteristic compressive strength of the material. A reverse manipulation of the above formula provides a 
reference value for the characteristic strength of each one of the considered mixtures as reported in Tables 3 and 4.

An alternative way to this kind of approach consists in the adoption of an enhanced statistical analysis that removes the hypothesis of assumed Gaussian distributions and takes into account suitable probability density functions to interpolate the experimental results. The distributions in Fig. 7 are used to recover a value for the characteristic strength of each one of the considered mixtures. The results shown in Tables 3 and 4 are in good agreement with the mean values of the strength reported in Fig. 4. The adoption of type "B" tests or more enhanced statistical procedures confirms that the adopted percentage of recycled aggregates allow to achieve similar performances with respect to standard concrete, especially in the case of cement CEM42.5R. The achieved compressive strength also suggests the adoption of these mixtures to cast structural elements made of reinforced concrete, since the Building Code requires a minimum concrete class of C16/20 for such applications.

Looking at Table 4, it must be remarked that mixture "Ash400" improves the compressive strength of the reference concrete, as proved by both the procedures herein adopted to derive the characteristic values $\mathrm{R}_{\mathrm{ck}}$. It is not clear the reason for such a performance, since many parameters may contribute to this achievement and a larger number of specimen should be investigated as well. However, looking at Fig. 3, one may easily notice that the mixture "Ash400" is much closer to the Bolomey curve if compared to the other mixtures, included that adopted as the reference. As discussed in Section 2.2, a granulometric variety that approximates with more accuracy the Bolomey function provides a lower void percentage, i.e. a lower porosity, thus increasing the composite strength. 


\subsection{Tensile strength}

Although the governing strength of a concrete mixture is its compressive value, the tensile threshold plays an important role in the structural behavior due to the need for crack control and durability requirements. Tensile strength affects the brittleness towards shocks or phenomena such as cracking for shrinkage, see e.g. [36]. Having the aim of evaluating this issue, some cylindrical specimens were used to perform suitable tests to measure the tensile strength. The achieved mean values $\left(\mathrm{R}_{\mathrm{tm}}\right)$ are reported in Fig. 8. It should be remarked that the small number of specimens involved in this part of the experimental campaign does not allow for any general conclusion. However, the results suggest that concretes containing recycled aggregates have lower tensile strength with respect to the reference mixtures. The composition of the residues remarkably affects the experimental results. The adoption of cement CEM42.5R considerably improves the performances of all the mixtures, especially in the case of mixture "San200". This allows exhausted sand to approximately performs as the reference concrete.

\section{Conclusion}

The final disposal of MSWI residues is nowadays an issue of crucial importance, due to the continuous increase in terms of waste production and to the relevant percentage of waste that is sent to incineration. Within this framework, this research was aimed at investigating a possible reuse of the exhausted sand and bottom ash produced by fluidized bed incinerators as alternative aggregates in concrete mixture. An experimental work was carried out focusing on concretes that are conventionally used in 
the production of unreinforced precast elements. The partial replacement of natural aggregate with bottom ash and exhausted sand has been herein addressed investigating the material strength. Particular attention was paid to material reliability, as also requested by international building codes. The reported statistical analysis must be intended as a first investigation performed for evaluating the acceptance controls prescribed by the codes. Indeed, a full assessment of the statistical properties of the considered mixtures would require a much wider population of tests.

The achieved simplified results show that the adoption of a suitable percentage of MSWI residues allows to recover characteristic values of the compressive strengths that are similar to the reference materials. The average compressive strength and the material reliability, i.e. the scattering of results, of concretes containing recycled aggregates are both comparable with those of the reference mixture. The same outcome in terms of characteristic values is obtained adopting the conventional Gaussian distribution or analyzing the performed tests through best-fitting procedures that suggest the use of Lognormal or Weibull distribution to describe the scattering of the results.

Conversely, an investigation on the tensile strength points out a lower performance for mix designs including recycled aggregates. The cement type is found to play a primary role in the reduction of the scattering of the experimental values around the average results. The adoption of $42.5 \mathrm{R}$ cement is found to remarkably improve results both in compressive and tensile tests, i.e. to reduce the gap between the performance of concretes containing recycled aggregates and the plain mix design.

The findings of this work suggest further efforts towards the assessment of nonconventional mix designs based on the reuse of these residues. Further investigations 
will focus on more extended experimental tests, with the main aim of finding the amount of recycled aggregates that optimize the strength of concrete while preserving the reliability of its structural performance. Moreover, long-term strength of concrete obtained with recycled materials should be evaluated.

\section{ACKNOWLEDGEMENTS}

The authors wish to thank Megazzini s.r.l. in Bressana Bottarone (Pavia) for the precasting of the concrete specimens and Società Lomellina Energia s.r.l. in Parona (Pavia) for supplying the residues. The experimental laboratory of the Department of Civil Engineering and Architecture at the University of Pavia is also acknowledged along with Giorgio Sforzini. A special acknowledgement is addressed to professor Giovanni Plizzari for his useful suggestions in writing this paper.

\section{REFERENCES}

1. CRESME. Il mercato del calcestruzzo preconfezionato negli anni della crisi - La struttura industriale e l'andamento del settore. Quinto Rapporto, 2011.

2. UEPG. A Sustainable Industry for a Sustainable Europe. European Aggregates Association: Annual Review, 2012.

3. DIRECTIVE 2008/98/EC of the European Parliament and of the Council of 19 November 2008 on waste and repealing, Official Journal of the European Union L $312 / 3$.

4. Decreto Ministeriale 14 gennaio 2008. Approvazione delle nuove norme tecniche per le costruzioni. Technical code for buildings, Italian law on the Official Gazette $29,04 / 02 / 2008$. 
5. Fraternali F, Farina I, Polzone C, Pagliuca E, Feo L. On the use of R-PET strips for the reinforcement of cement mortars. Composite: Part B 2013; 46: 207-210.

6. Guoqiang L, Garrick G, Eggers J, Abadie C, Stubblefield MA, Pang S. Waste tire fiber modified concrete. Composite: Part B 2004; 35: 305-312.

7. ISPRA. Rapporto Rifiuti Urbani 2012. Report n. 163. ISBN 978-88-448-0550-0, 2012.

8. Pera J, Coutaz L, Ambroise J, Chababbet M. Use of incinerator bottom ash in concrete. Cem and Concr Res 1997; 27(1): 1-5.

9. Bertolini L, Carsana M, Cassago D, Quadrio Curzio A, Collepardi M. MSWI ashes as mineral additions in concrete. Cem and Concr Res 2004; 34: 1899-1906.

10. Ferraris M, Salvo M, Ventrella A, Buzzi L, Veglia M. Use of vitrified MSWI bottom ashes for concrete production. Waste Management 2009; 29: 1041-1047.

11. Siddique R. Use of municipal solid waste ash in concrete. Resour, Conservation and Recycling 2010, 55 (2): 83-91.

12. Kuo WT, Liu CC, Su DS. Use of washed municipal solid waste incinerator bottom ash in pervious concrete. Cem and Concr Composites 2013; 37: 328-335.

13. Weng MC, Lin CL, Ho CI. Mechanical properties of incineration bottom ash: the influence of composite species. Waste Management 2010; 30(7): 1303-1309.

14. Sorlini S, Abbà A, Collivignarelli C. Recovery of MSWI and soil washing residues as concrete aggregates. Waste Management 2011; 31: 289-297.

15. Ginés O, Chimenos JM, Vizcarro A, Formosa J, Rosell JR. Combined use of MSWI bottom ash and fly ash as aggregate in concrete formulation: environmental and mechanical considerations. J of Hazard Mater 2009; 169: 643-650. 
16. Aubert J.E., Husson B., Vaquier A. Use of municipal solid waste incineration fly ash in concrete. Cem and Concr Res 2004; 34: 957-963.

17. del Valle-Zermeño R., Formosa J., Chimenos J.M., Martínez M., Fernández A.I. Aggregate material formulated with MSWI bottom ash and APC fly ash for use as secondary building material. Waste Management 2013; 33: 621-627.

18. Toraldo E., Saponaro S., Careghini A., Mariani E. Use of stabilized bottom ash for bound layers of road pavements. J of Environmental Management 2013; 121: 117123.

19. Chang FY, Wey MY. Comparison of the characteristics of bottom and fly ashes generated from various incineration processes. J of Hazard Mate 2006; 138(3): 594603.

20. Gambhir ML. Concrete Technology - Theory and Practice. Fourth Edition, Tata McGraw-Hill, New Delhi, 2009.

21. Tabhs SW, Aswad A. Statistical Properties of Plant-Produced High Strength Concrete in Compression. PCI J 1995; July-August: 72-73.

22. Lin YH, Tyan YY, Chang TP, Chang CY. An assessment of optimal mixture for concrete made with recycled concrete aggregates. Cem and Concr Res 2004; 34: 1373-1380.

23. Savastano JrH, Warden PG, Coutts RSP. Brazilian waste fibres as reinforcement for cement-based composites. Cem and Concr Composites 2000; 22(5): 379-384.

24. Bhanja S, Sengupta B. Investigation on the compressive strength of silica fume concrete using statistical methods. Cem and Concr Res 2002; 32: 1391-1394. 
25. Chandler AJ, Eighmy TT; Hartlén J, Hjelmar O., Kosson DS, Sawell SE, van der Sloot HA, Vehlow J. Municipal solid waste incineration residues. The International Ash Working Group, Elsevier, ISBN 0-444-82563-0, 1997.

26. Palacios M., Puertas F. Effect of superplasticizer and shrinkage-reducing admixtures on alkali-activated slag pastes and mortars. Cem and Concr Res 2005; 35: 13581367.

27. Pereira P., Evangelista L., de Brito J. The effect of superplasticizers on the mechanical performance of concrete made with fine recycled concrete aggregates. Cem and Concr Res 2012; 34(9): 1044-1052.

28. UNI EN 12390-2. Prove sul calcestruzzo indurito - Parte 2: Confezione e stagionatura dei provini per prove di resistenza. May, Italian standardized board for concrete testing, 2009.

29. UNI EN 12390-3. Prove sul calcestruzzo indurito - Parte 3: Resistenza alla compressione dei provini. May, Italian standardized board for concrete testing, 2009.

30. UNI EN 12390-6. Prove sul calcestruzzo indurito - Parte 6: Resistenza a trazione indiretta dei provini. January, Italian standardized board for concrete testing, 2010.

31. Ellingwood B, Galambos TV, MacGregor JG, Cornell CA. Development of a probability based load criterion for American National Standard A58. Publication 577, National Bureau of Standards, Department of Commerce, Washington, 1980.

32. Benjamin J, Cornell C. Probability statistics and decision for civil engineers. McGraw-Hill, New York, 1970.

33. Mirza SA, Hatzinikolas M, MacGregor JG. Statistical Descriptions of Strength of Concrete. ASCE J of the Structural Division 1979; 105(ST6):1021-1037. 
34. Nowak S, Szerszen MM. Calibration of design code for buildings (ACI 318) Part 1: Statistical Models for Resistance. ACI Structural J 2003; 100(3): 377-382.

35. Tumidajski PJ, Fiore L, Khodabocus T, Lachemi M, Pari R. Comparison of weibull and normal distributions for concrete compressive strengths. Canadian J of Civ Eng 2006; 33(10): 1287-1292.

36. Ramalho M.A., Papa E., Taliercio A. A non-local anisotropic damage model for brittle materials. WIT Transactions on the Built Environ 2007; 95: 505-514.

37. Reimann C., de Caritat P. New soil composition data for Europe and Australia: Demonstrating comparability, identifying continental-scale processes and learning lessons for global geochemical mapping. Science of the Total Environ 2012; 416: 239-252. 


\begin{tabular}{|c|c|c|c|c|}
\hline \multirow[b]{2}{*}{ Parameter } & \multirow{2}{*}{$\begin{array}{c}\text { Unit of } \\
\text { measurement }\end{array}$} & \multicolumn{3}{|c|}{ Content } \\
\hline & & $\begin{array}{c}\text { Exhausted } \\
\text { sand }\end{array}$ & $\begin{array}{c}\text { Bottom } \\
\text { ash }\end{array}$ & $\begin{array}{c}\text { Natural } \\
\text { soil [37] [25] }\end{array}$ \\
\hline \multicolumn{5}{|c|}{ Major elements } \\
\hline $\mathrm{SiO}_{2}$ & [wt\%] & 91 & 42 & $1-99$ \\
\hline $\mathrm{Al}_{2} \mathrm{O}_{3}$ & [wt\%] & 2.7 & 16 & $0.3-28$ \\
\hline $\mathrm{Fe}_{2} \mathrm{O}_{3}$ & [wt\%] & 1.5 & 9 & $0.1-33$ \\
\hline $\mathrm{CaO}$ & [wt\%] & 0.2 & 18 & $0.01-50$ \\
\hline $\mathrm{MgO}$ & [wt\%] & 0.1 & 5 & $0.01-24$ \\
\hline $\mathrm{Na}_{2} \mathrm{O}$ & [wt\%] & - & 6 & $0.01-6$ \\
\hline $\mathrm{K}_{2} \mathrm{O}$ & [wt\%] & 0.6 & 1 & $0.03-10$ \\
\hline \multicolumn{5}{|c|}{ Minor elements } \\
\hline Nickel & {$[\mathrm{mg} / \mathrm{kg}]$} & 70 & 11 & $5-500$ \\
\hline Total copper & {$[\mathrm{mg} / \mathrm{kg}]$} & 1,500 & 1,700 & $2-100$ \\
\hline Soluble copper & {$[\mathrm{mg} / \mathrm{kg}]$} & $<3$ & 3 & - \\
\hline Lead & {$[\mathrm{mg} / \mathrm{kg}]$} & 96 & 589 & $2-200$ \\
\hline Cadmium & {$[\mathrm{mg} / \mathrm{kg}]$} & 2.9 & $<0.6$ & $0.01-0.7$ \\
\hline Total Chromium & {$[\mathrm{mg} / \mathrm{kg}]$} & 415 & 39 & $1-1,000$ \\
\hline Chromium VI & {$[\mathrm{mg} / \mathrm{kg}]$} & 0.1 & $<0.1$ & - \\
\hline Antimony & {$[\mathrm{mg} / \mathrm{kg}]$} & 67 & 16 & - \\
\hline Zinc & {$[\mathrm{mg} / \mathrm{kg}]$} & 1,661 & 185 & $10-300$ \\
\hline Arsenic & {$[\mathrm{mg} / \mathrm{kg}]$} & $<1$ & $<1$ & $1-50$ \\
\hline Tin & {$[\mathrm{mg} / \mathrm{kg}]$} & 167 & 47 & $2-200$ \\
\hline
\end{tabular}

Table 1. Average chemical composition of residues used in the experimental work. 


\begin{tabular}{|c|c|c|c|c|c|c|c|}
\hline \multirow{2}{*}{$\begin{array}{c}\text { Mix } \\
\text { design }\end{array}$} & \multicolumn{2}{|c|}{$\begin{array}{c}\text { Natural } \\
\text { aggregates } \\
\text { amount }\left[\mathrm{kg} / \mathrm{m}^{3}\right]\end{array}$} & \multicolumn{2}{|c|}{$\begin{array}{l}\text { Recycled aggregates } \\
\text { amount }\left[\mathrm{kg} / \mathrm{m}^{3}\right]\end{array}$} & \multirow{2}{*}{$\begin{array}{l}\text { Cement } \\
\text { amount } \\
{\left[\mathrm{kg} / \mathrm{m}^{3}\right]}\end{array}$} & \multirow{2}{*}{$\begin{array}{c}\text { Water } \\
\text { amount } \\
{\left[\mathrm{kg} / \mathrm{m}^{3}\right]}\end{array}$} & \multirow{2}{*}{$\begin{array}{l}\text { Water/cement } \\
\text { ratio }\end{array}$} \\
\hline & Sand & $\begin{array}{c}\text { Fine } \\
\text { gravel }\end{array}$ & $\begin{array}{c}\text { Exhausted } \\
\text { sand }\end{array}$ & $\begin{array}{c}\text { Bottom } \\
\text { ash }\end{array}$ & & & \\
\hline Ref & 900 & 600 & - & - & 320 & 240 & 0.75 \\
\hline Ash400 & 700 & 400 & - & 400 & 320 & 240 & 0.75 \\
\hline San200 & 700 & 600 & 200 & - & 320 & 240 & 0.75 \\
\hline
\end{tabular}

Table 2. Mix design for the concrete mixtures investigated in the experimental work. 


\begin{tabular}{cccccc}
\hline \multirow{2}{*}{$\begin{array}{c}\text { Mix design } \\
\text { (CEM32.5R) }\end{array}$} & \begin{tabular}{c} 
Re1 \\
\cline { 2 - 6 }$[\mathbf{M P a}]$
\end{tabular} & $\begin{array}{c}\text { Rcm } \\
{[\mathbf{M P a}]}\end{array}$ & $\begin{array}{c}\text { Rck } \\
{[\mathbf{M P a}]}\end{array}$ & $\begin{array}{c}\text { Probability } \\
\text { distribution }\end{array}$ & $\begin{array}{c}\text { Rck } \\
{[\mathbf{M P a}]}\end{array}$ \\
\hline Ref & 15.56 & 16.70 & 15.75 & Lognormal & 15.61 \\
Ash400 & 14.22 & 16.77 & 14.34 & Lognormal & 14.25 \\
San200 & 14.22 & 16.52 & 15.26 & Weibull & 15.02 \\
\hline
\end{tabular}

Table 3. Statistical controls on the compressive strength of concrete mixtures (CEM32.5R). 


\begin{tabular}{cccccc}
\hline \multirow{2}{*}{$\begin{array}{c}\text { Mix design } \\
\text { (CEM42.5R) }\end{array}$} & \begin{tabular}{c} 
Re1 \\
\cline { 2 - 6 }
\end{tabular} & $\begin{array}{c}\text { Rcm } \\
{[\mathbf{M P a}]}\end{array}$ & $\begin{array}{c}\text { Rck } \\
{[\mathbf{M P a}]}\end{array}$ & $\begin{array}{c}\text { Probability } \\
{[\mathbf{M P a}]}\end{array}$ & $\begin{array}{c}\text { Rck } \\
\text { distribution } \\
{[\mathbf{M P a}]}\end{array}$ \\
\hline Ref & 20.44 & 22.30 & 21.27 & Weibull & 20.92 \\
Ash400 & 20.89 & 22.70 & 21.46 & Lognormal & 21.28 \\
San200 & 20.44 & 21.82 & 20.89 & Lognormal & 20.75 \\
\hline
\end{tabular}

Table 4. Statistical controls on the compressive strength of concrete mixtures (CEM42.5R). 
Figure 1. Residues used in the experimental work: exhausted sand (a) and bottom ash (b).

Figure 2. Particle size distribution of the aggregates.

Figure 3. Particle size distribution of concrete solid fraction.

Figure 4. Mean values Compressive strength:.

Figure 5. Coefficient of variation of concrete compressive strength.

Figure 6. Gaussian probability distributions of concrete compressive strength (CEM32.5R(a); CEM 42.5R(b)).

Figure 7. Estimated probability distributions of thecompressive strength (CEM32.5R(a); CEM $42.5 \mathrm{R}(\mathrm{b}))$.

Figure 8. Mean values of concrete tensile strength:. 
Click here to download high resolution image

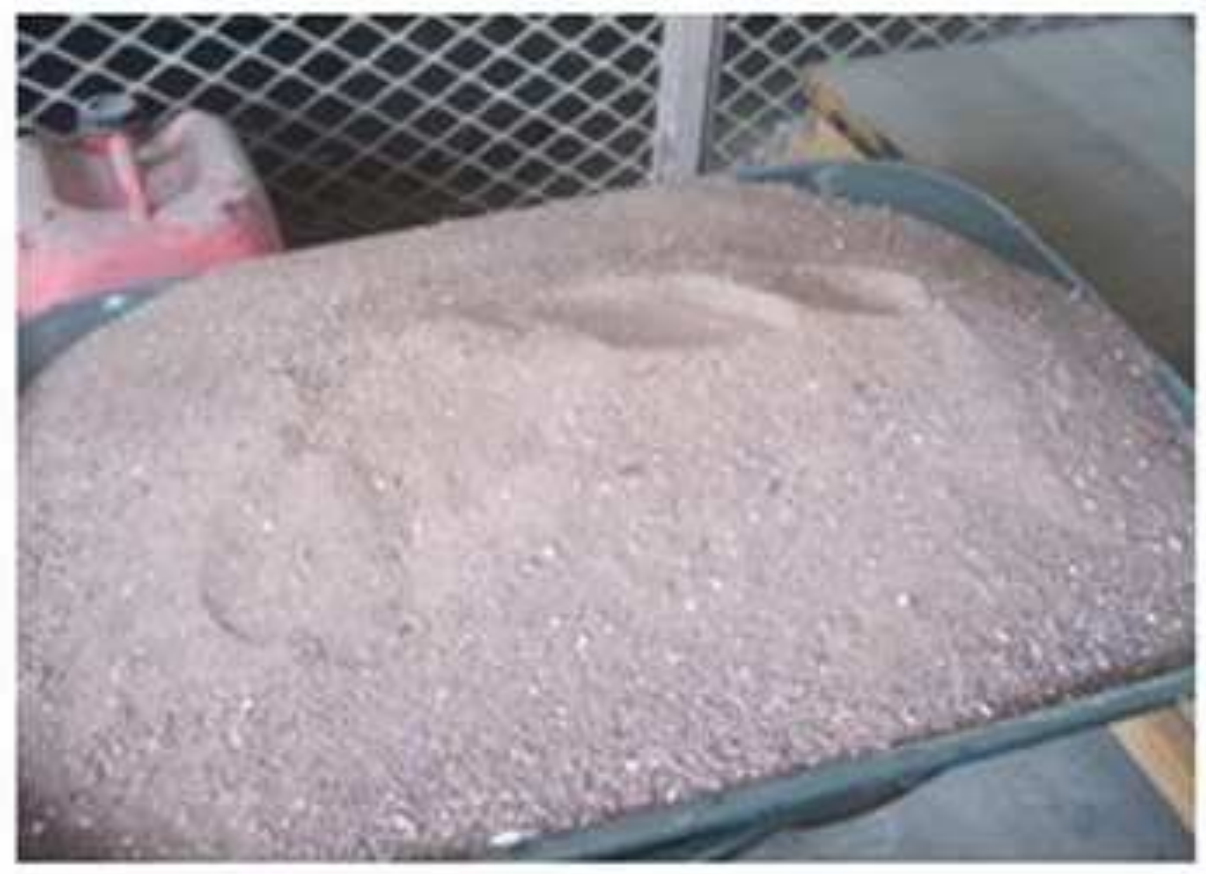

(a)

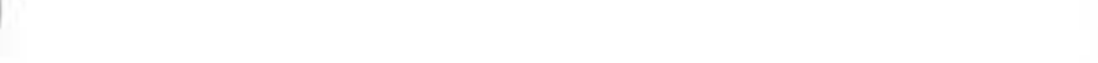

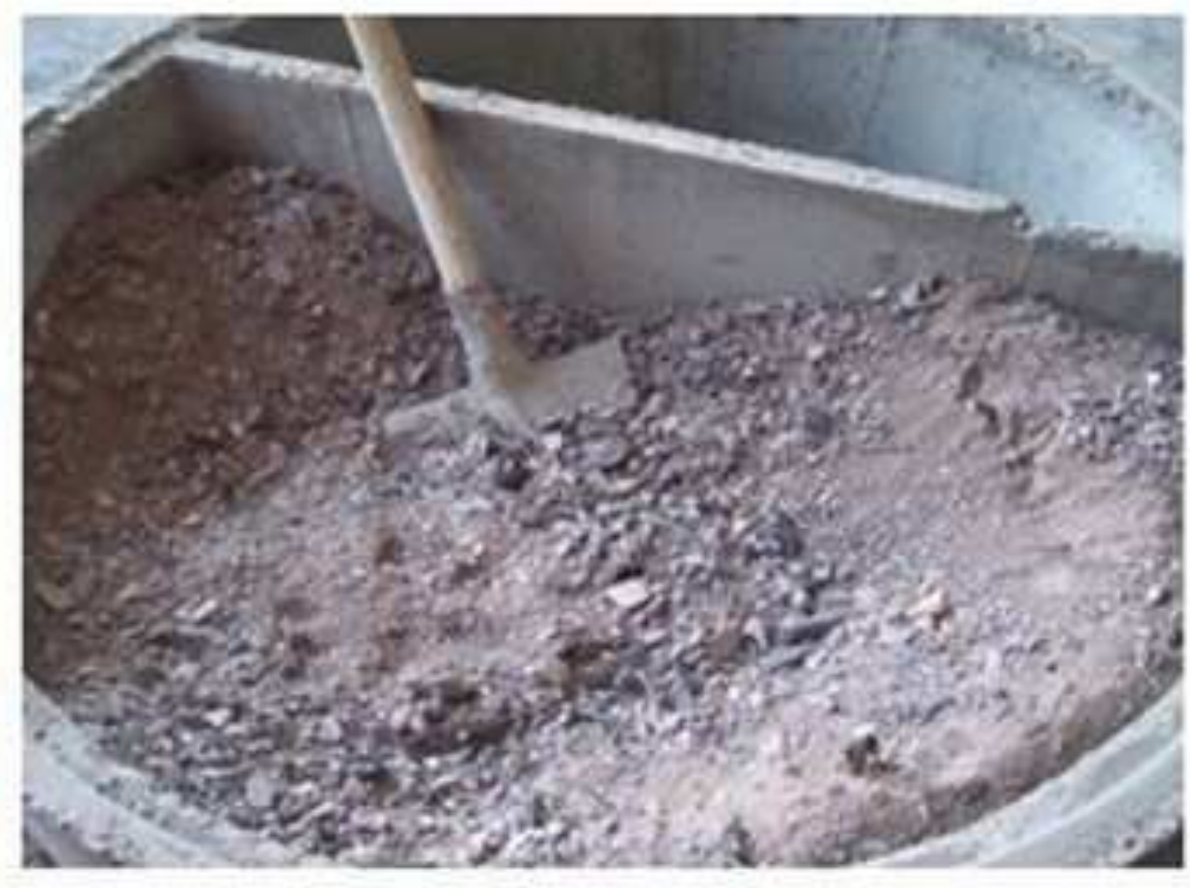

(b)

. 


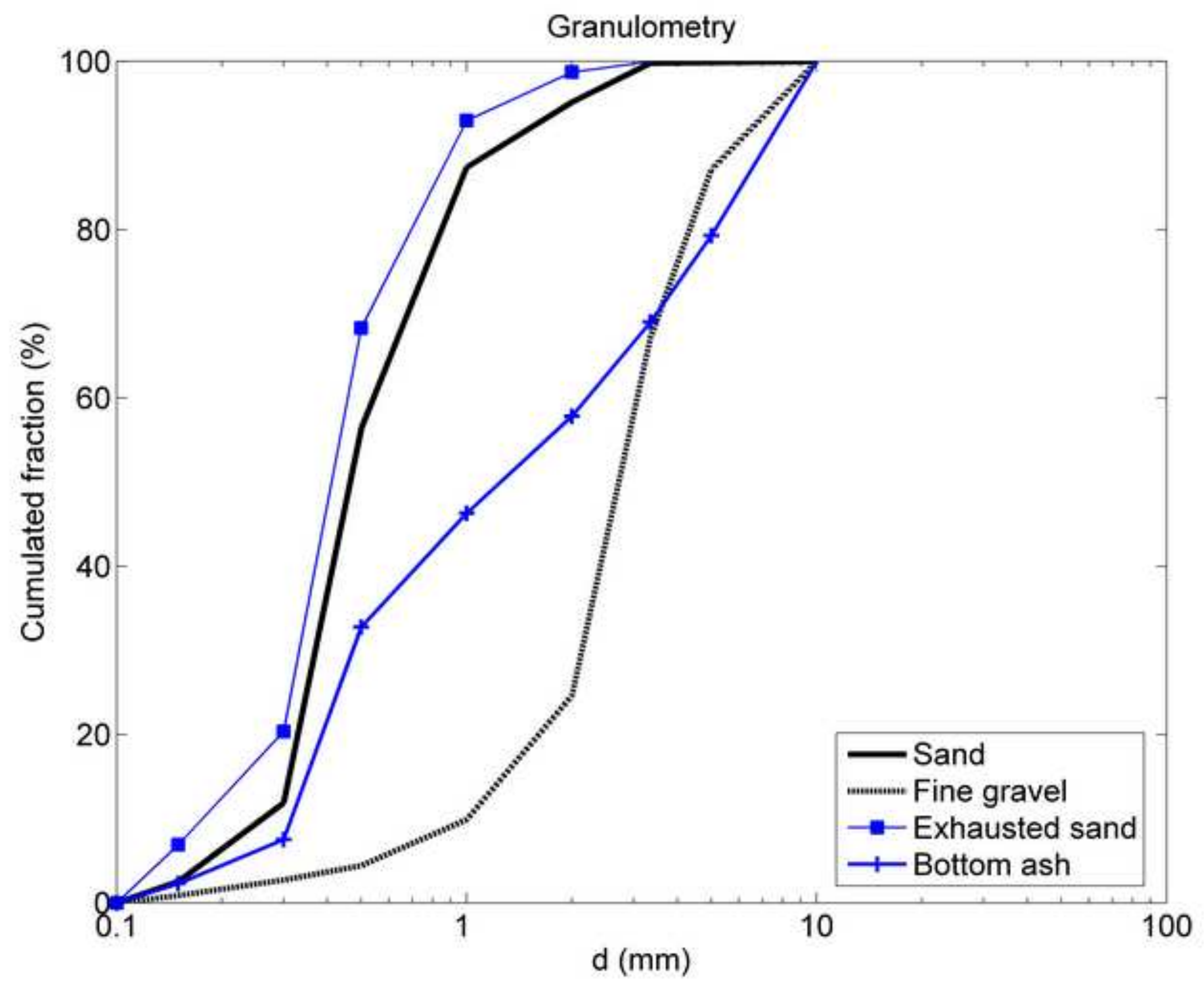




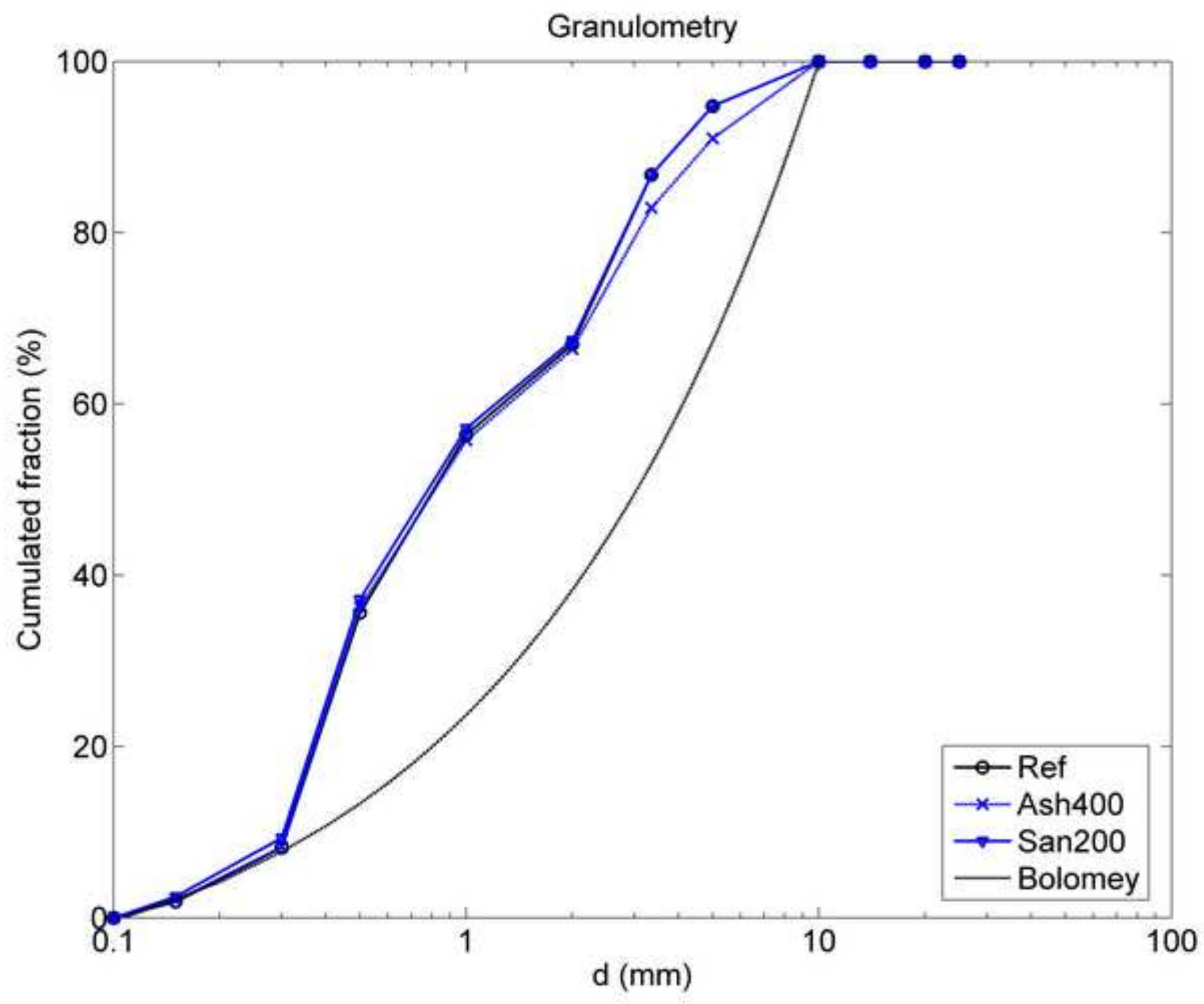




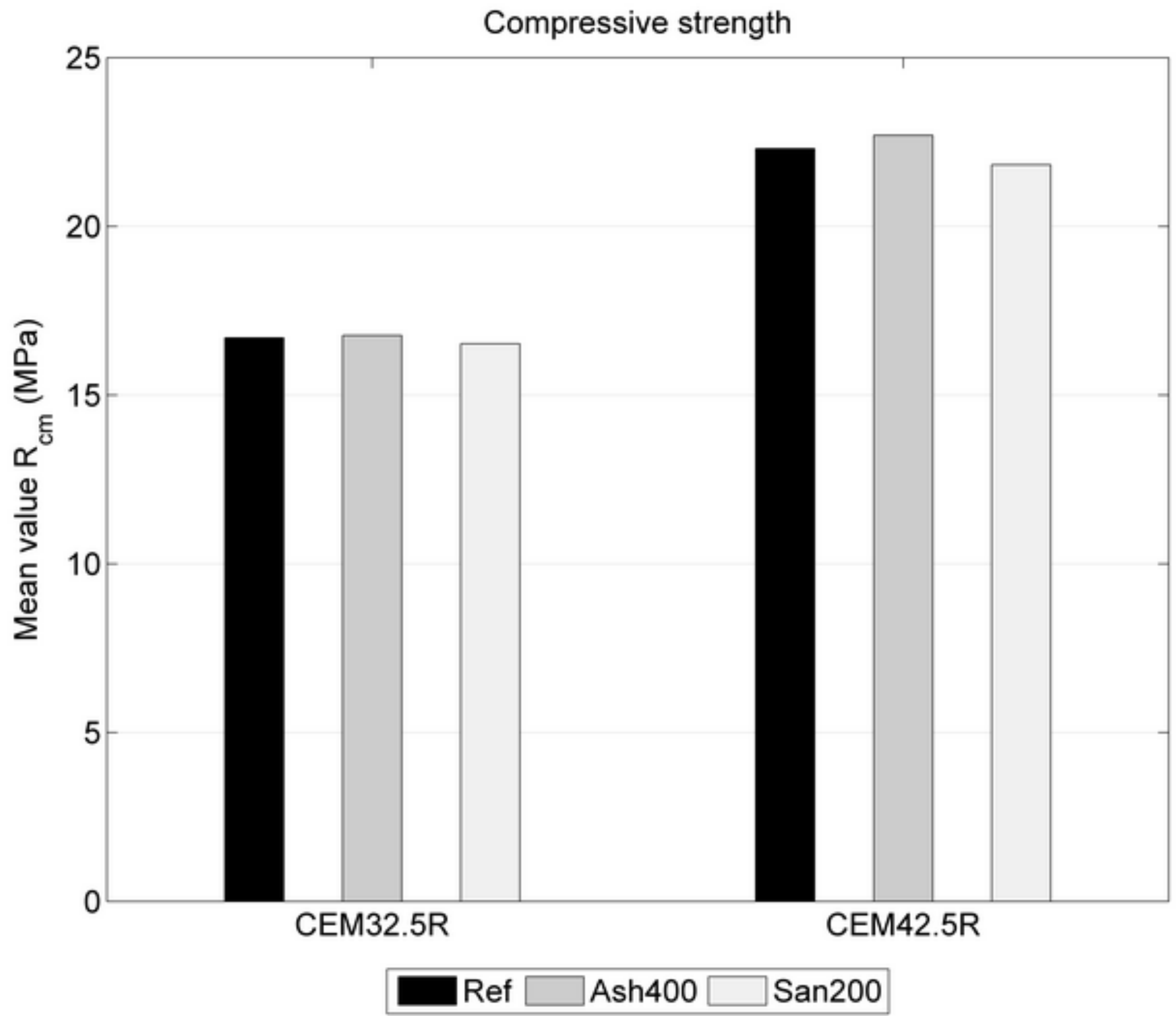


Compressive strength

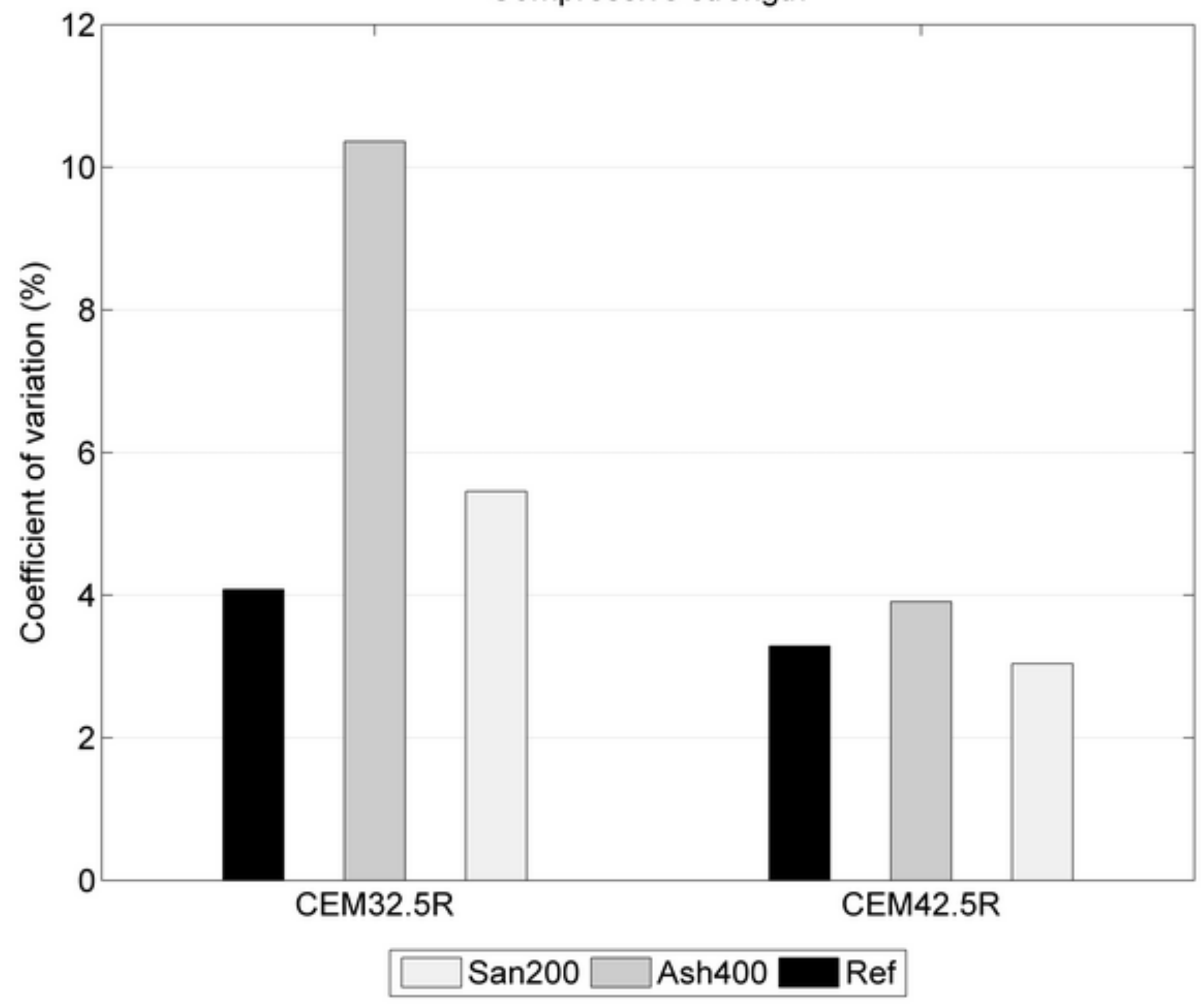




\section{Figure}

Click here to download high resolution image
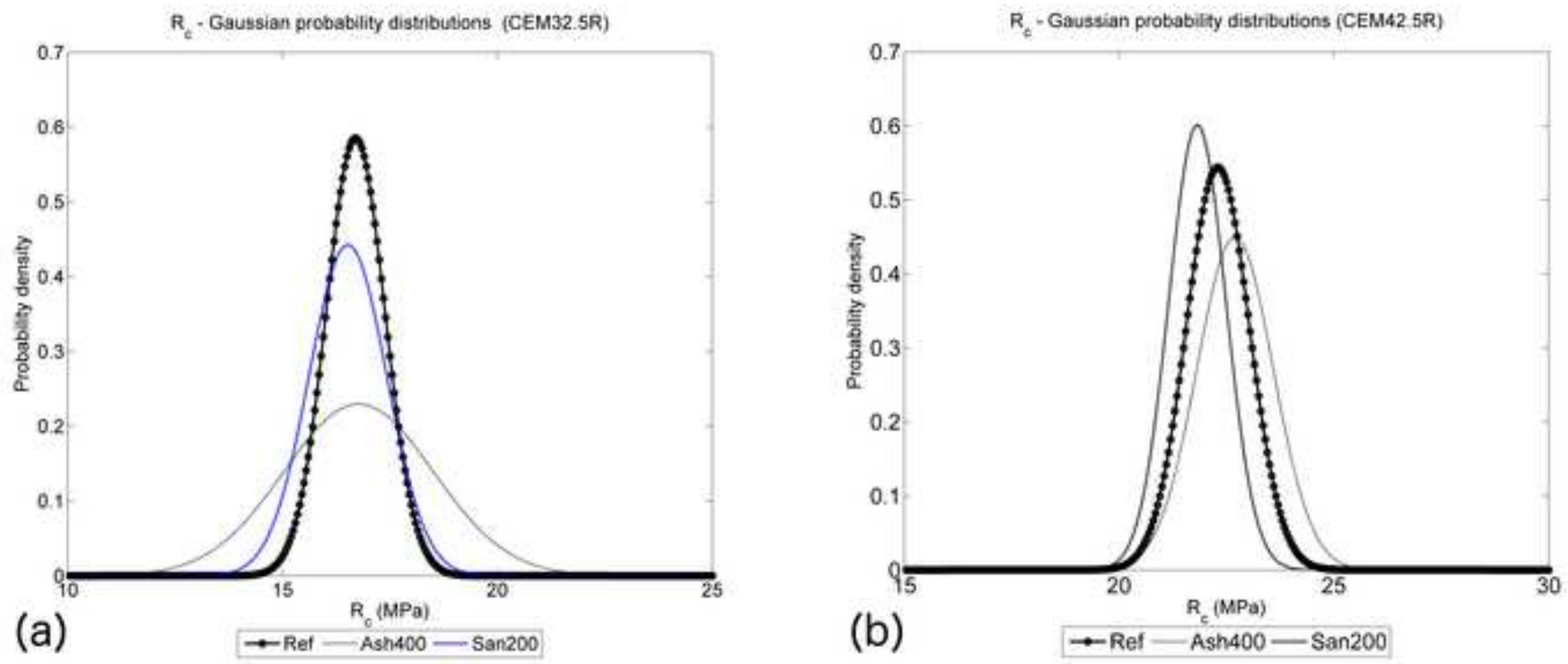


\section{Fure}

Click here to download high resolution image
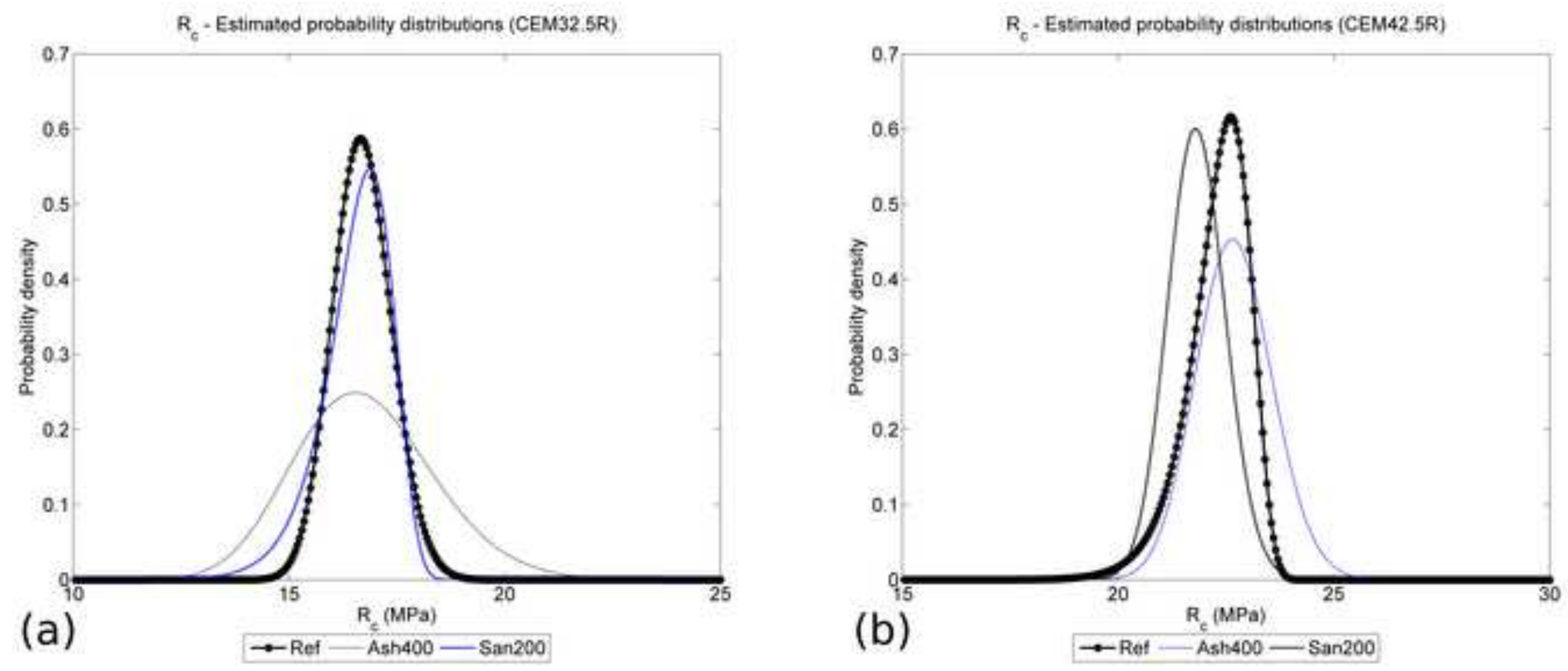
Tensile strength

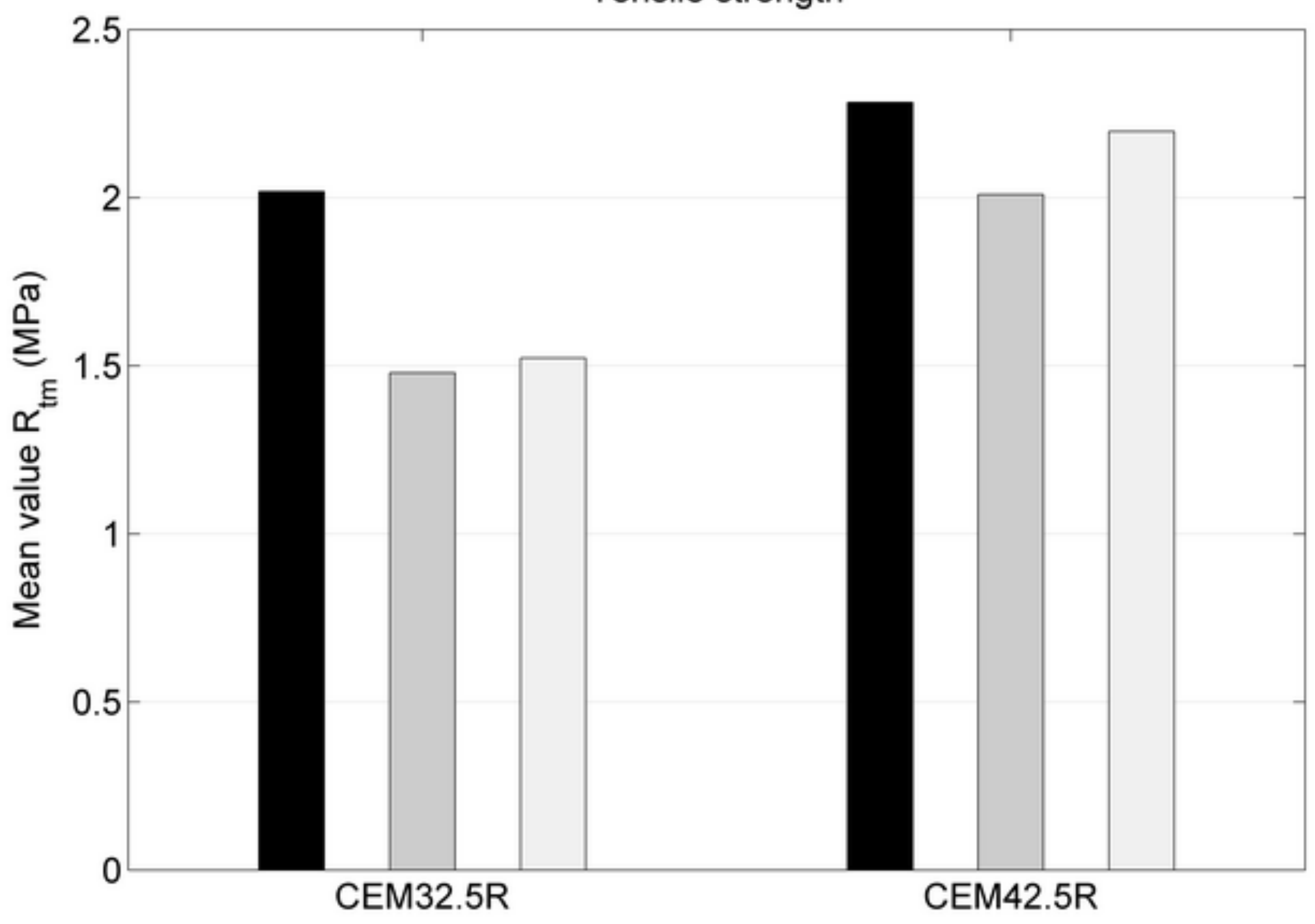

Ref $\square$ Ash400 $\square$ San200 